\title{
Permeability Characteristics of the Human Small Intestine*
}

\author{
John S. Fordtran, $\dagger$ Floyd C. Rector, Jr., Maynard F. Ewton, $\ddagger$ \\ Nicholas Soter,§ and John Kinney § \\ (From the Department of Internal Medicine, The University of Texas Southwestern Medical \\ School, Dallas, Texas)
}

Relatively little information is available concerning the membrane structure of the mucosal cells of the small intestine. Höber and Höber (1) and Schanker, Tocco, Brodie, and Hogben $(2,3)$ studied the absorption of a variety of substances in rats and found that absorption rate increased as lipid solubility increased. From this it has been deduced that mucosal cell membranes are lipoid in nature and that lipid-soluble substances are absorbed by dissolving in the cell membrane. However, it has been known for many years that small molecules, although lipid insoluble, can also be absorbed from the gastrointestinal tract. This has led to the hypothesis that, although essentially lipoidal, cell membranes are interspersed with water-filled pores, through which small molecules can diffuse. Höber and Höber (1) tested this hypothesis in the small intestine of the rat by correlating the absorption rate of nonlipid-soluble substances with their molecular size. Their results support the thesis that these molecules are absorbed by diffusion through water-filled pores. since small molecules were absorbed more rapidly than larger ones, and beyond a certain size (molecular weight about 180 , which corresponds to a molecular radius of about $4 \mathrm{~A}$ ) no penetration occurred. Lindemann and Solomon's studies (4) are in close agreement, since they experimentally determined, by an independent method, the pore radius of the luminal surface of the rat jejunal cells

* Submitted for publication April 14, 1965, accepted August 19, 1965.

Supported by research grant AM-06506 and training grant TI-AM-5395 from the National Institutes of Health.

† Address requests for reprints to Dr. John S. Fordtran, Dept. of Internal Medicine, University of Texas Southwestern Medical School, Dallas, Texas 75235.

$\ddagger$ The work was done during the tenure of a postdoctoral traineeship under grant TI-AM-5395.

$\S$ The work was done during the tenure of a summer predoctoral traineeship under grant TI-AM-5395. to be approximately $4 \mathrm{~A}$. This is the only available estimate of intestinal pore size in any species, and no estimates at all are available for pore size at different levels of the small intestine.

The purpose of our studies, therefore, was to evaluate the permeability of the human intestinal mucosa by measuring the effective pore size at different levels of the small intestine. The theoretical basis for the present studies rests on the demonstration by Staverman (5) and Solomon (6) that the ability of a nonlipid-soluble solute to exert an effective osmotic pressure gradient ${ }^{1}$ across a membrane is a function of its molecular radius relative to the radius of the water-filled pores in that membrane. Thus, the degree to which a solute of known molecular size is capable of exerting its full theoretic osmotic pressure gradient, which is defined as the reflection coefficient $(\sigma)$, can be used to calculate the pore size of the membrane, which. in turn, determines the permeability of the membrane to nonlipid-soluble solutes.

To determine $\sigma$ for a test solute, water movement into an intestinal segment perfused with a hypertonic solution of the test solute was compared with the water movement into the same segment in response to hypertonic mannitol. Since mannitol was demonstrated not to penetrate the small intestinal mucosa to a measurable extent, its effective and theoretic osmotic pressure should be equal, and it was therefore assumed to have a $\sigma$ of 1.0. By these techniques we found that the

1 The effective osmotic pressure is the actual pressure exerted across a membrane separating two solutions of differing concentration. If the membrane is perfectly semipermeable, the effective and theoretic osmotic pressures are equal. However, for membranes that are not perfectly semipermeable, the effective osmotic pressure will be less than the theoretic value. The effective osmotic pressure divided by the theoretic osmotic pressure has been defined by Staverman (5) as the reflection coefficient. 
effective pore size in the upper small intestine is at least twice that in the lower small intestine.

\section{Methods}

Measurement of osmotic flow of water. The movement of water into the intestinal lumen in response to hypertonic solutions of urea, erythritol, and sodium chloride was compared in a given gut segment to that induced by solutions of mannitol of the same tonicity; these comparative studies were performed at different levels of the small intestine of 20 normal male and female subjects between the ages of 21 and 40 . The net water movement into the gut lumen was measured by the dilution of a nonabsorbable marker, a technique that has been previously validated (7-9).

Subjects were intubated with a triple-lumen polyvinyl tube prepared by fusing single tubes with tetrahydrofuran. The opening of the tube used for infusion of the test solutions was 10 and $30 \mathrm{~cm}$ proximal to that of the two collecting tubes. The internal diameter of the infusion tube was $0.7 \mathrm{~mm}$; that of the collecting tubes was $1.8 \mathrm{~mm}$. A $2-\mathrm{cm}$ piece of $16 \mathrm{~F}$ polyvinyl tubing containing multiple small holes (no larger than $1.8 \mathrm{~mm}$ ) was attached to the opening of each collecting tube to facilitate drainage. The location of the tube was determined fluoroscopically after contrast material had been injected into the tube with the most distal opening, and was expressed as the length of tubing between the incisor teeth and the infusion point when slack had been removed from the portion of the tube that was in the stomach. Expressed in this way, the pylorus is approximately 60 , the ligament of Treitz 90 , and the ileocecal valve $350 \mathrm{~cm}$ from the teeth.

The experimental protocol was as follows:

1) All studies were performed after subjects had fasted for 8 hours.

2) The first study was performed when the infusion point was 85 to $100 \mathrm{~cm}$ from the teeth, which is in the general area of the ligament of Treitz.

3) Hypertonic mannitol was infused for 90 minutes. The first 30 minutes of this period was used for equilibration; this was followed by a 1-hour test period during which samples were collected from the proximal and distal collecting sites.

4) Immediately thereafter, the material infused was changed to a hypertonic solution of a penetrating solute (urea, erythritol, or sodium chloride), and after a 30-minute washout and equilibration period a second 1-hour collection was made from the proximal and distal collecting sites.

5) After completion of this initial study, subjects were permitted to eat clear liquids, and the tube was allowed to pass into a lower segment of the small intestine.

6) After another 8-hour period, during which the subjects fasted, the lower segment was perfused sequentially with hypertonic solutions of mannitol and test solute, as described in steps 3 and 4 above.
The sequence was repeated at three or four levels of the small intestine of each subject, so that an entire study might last as long as 3 to 4 days. The order in which the hypertonic solutions were perfused was alternated among subjects.

All hypertonic solutions contained a nonabsorbable reference material, polyethylene glycol (PEG, molecular weight 4,000) (8), and were infused at a constant rate of $9 \mathrm{ml}$ per minute via a Bowman infusion pump. Between the infusion point and the proximal sampling site, the infused solution mixed to a variable extent with digestive secretions as well as with water and solutes, which move across the mucosa of the intestine into the hypertonic perfusate. After passing the proximal site, however, the osmolality of the perfusate can be altered only by water or solute moving across the small intestinal mucosal cells. To prevent water movement secondary to chemical gradients of sodium, all test solutions, except hypertonic sodium chloride solutions, contained 140 mmoles per $\mathrm{L}$ of sodium chloride. That the volume change between the proximal and distal sampling sites is not significantly influenced by absorption or secretion of sodium salts and water is evident from a separate series of experiments (10) showing that, in the absence of glucose, jejunal and ileal absorption rates of water from isotonic electrolyte solutions are, extremely small and negligible compared to the rates of bulk water movement in response to osmotic pressure gradients. This observation is in accord with experiments by Fisher (11), who found that in rats the absorption of isotonic Kreb's solution containing no glucose is "not significantly different from zero," whereas even small amounts of glucose markedly stimulate water absorption. Therefore, dilution of the solution between the proximal and distal collecting sites, as measured by the dilution of the nonabsorbable PEG, is a measure of the volume of water moving across the mucosal cells in the $20-\mathrm{cm}$ segment of intestine in response to the hypertonic luminal contents. The equations used in this calculation were as follows:

$$
\begin{gathered}
\dot{Q}_{\varepsilon}=\frac{I \times[P E G]_{i}}{[P E G]_{p}}-S_{p}, \\
\dot{Q}_{\mathrm{L}}=\frac{Q_{E} \times[P E G]_{p}}{[P E G]_{d}}, \text { and } \\
Q_{N}=Q_{\mathrm{L}}-Q_{E},
\end{gathered}
$$

where $I$ is the infusion rate in milliliters per minute; $\dot{Q}_{x}$ and $\dot{Q}_{\mathrm{L}}$ are the flow rates, in milliliters per minute entering and leaving the $20-\mathrm{cm}$ test segment, respectively; $[P E G]_{1},[P E G]_{p}$; and $[P E G]_{d}$ are, respectively, the PEG concentrations of the infused solution, and the fluid obtained from the proximal and distal collecting sites; $S_{p}$ is the rate of sampling from the proximal collecting site in milliliters per minute; and $\dot{Q}_{\mathrm{N}}$ is the net movement of water across the mucosa of the $20-\mathrm{cm}$ intestinal segment in milliliters per minute.

In the upper intestine there was greater dilution of the material infused between the infusion point and the proximal collecting site than in the lower intestine. Further- 
more, the degree of dilution of the perfused fluid varied with different hypertonic solutions. This poses two problems: the maintenance of equal mean flow rates and equal mean osmotic pressure gradients in the test segment. To maintain equal flow rates through the upper and lower intestine with different hypertonic solutions, it was necessary to vary the rate of collection through the proximal collecting tube. In the upper jejunum the rate of sampling from the proximal tube was $4 \mathrm{ml}$ per minute for mannitol, $2.5 \mathrm{ml}$ per minute for erythritol, and $1.5 \mathrm{ml}$ per minute for urea and sodium chloride solutions. In the midintestine, corresponding sampling rates were 2.5 for mannitol and $\mathbf{1 . 5}$ for all other solutions. In the lower small intestine, the sampling rate was $1.5 \mathrm{ml}$ per minute regardless of solution. These sampling rates were selected after trial and error, because they yielded approximately equal mean perfusion rates through the $20-\mathrm{cm}$ test segments.

It was also found by trial and error that approximately equal osmotic pressure gradients in the upper and lower intestinal segments were achieved when the osmolality of the infused material was varied as follows: upper intestine, $800 \mathrm{mOsm}$ per $\mathbf{~ k g}$, and lower intestine, $550 \mathrm{mOsm}$ per $\mathrm{kg}$. Infusion of solutions with these osmolalities resulted in mean osmotic gradients between luminal contents and blood of 95 to $300 \mathrm{mOsm}$ per $\mathrm{kg}$.

In all studies, an intravenous infusion of $3.5 \%$ glucose solution in water was given at a constant rate to prevent dehydration. The rate of infusion was $600 \mathrm{ml}$ per hour in jejunal studies and $300 \mathrm{ml}$ per hour for mid- and lower intestinal studies. Blood was collected at the beginning and end of each perfusion; in no case did serum osmolality exceed $300 \mathrm{mOsm}$ per $\mathrm{kg}$, nor did dilution occur. To minimize variation in the level of circulating antidiuretic hormone, $200 \mathrm{mU}$ per hour of aqueous Pitressin was given intravenously.

Analytical methods. PEG was determined in duplicate by the method of Hyden (12). In our hands this method is reproducible within $\pm 2 \%$ on duplicate testing. Mannitol was analyzed by the method of Corcoran and Page (13), sodium by flame photometer, and osmolality by freezing point depression in a Fiske osmometer.

\section{Results}

Determination of filtration coefficients for bulk flow of water at different levels of the small intestine. To determine accurately the filtration coefficient for bulk flow of water (i.e., the quantity of water that will be moved across a given length of intestinal mucosa under the influence of known effective osmotic pressure), it is necessary to establish the concentration gradient with a substance that does not penetrate the membrane and is therefore capable of exerting its full theoretic osmotic pressure. Mannitol was chosen because in most animal studies it has been found not to be ab-

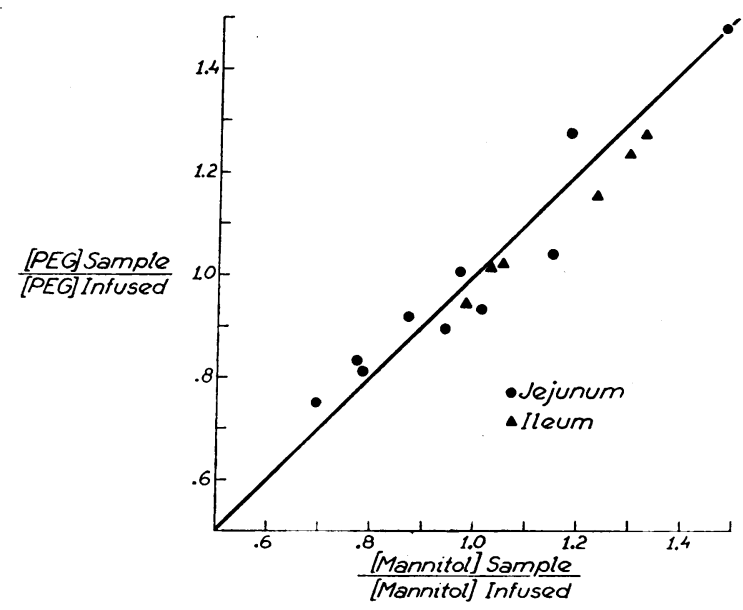

Fig. 1. Absorption of mannitol. Solutions containing mannitol and polyethylene glycol (PEG) were in fused into the jejunum (ten studies) and ileum (six studies) of normal subjects. The relative dilution or concentration of these solutes after traversing $20-\mathrm{cm}$ segments of intestine is shown. A line of perfect agreement is indicated. The dilution or concentration of mannitol was approximately the same as that of PEG, indicating that mannitol is not absorbed to a measurable extent within $20-\mathrm{cm}$ segments of human small intestine.

sorbed $(3,14)$ or at the most, absorbed at a very low rate (15). As shown in Figure 1, mannitol absorption did not occur in 20-cm segments of human jejunum (ten studies) and ileum (six studies) of normal human subjects. It should therefore exert its full theoretic osmotic pressure.

When solutions made hypertonic by the addition of mannitol were perfused through the small intestine, there was rapid movement of water into the lumen of the test segment, which decreased the osmolality of the luminal contents. Consequently, the osmotic pressure gradient between plasma and luminal contents was not constant, but fell progressively from proximal to distal points in the test segment. Four studies were performed to determine the profile of the osmotic pressure gradient along the length of a perfused segment. In these studies intestinal contents were sampled at four sites, $10 \mathrm{~cm}$ apart, beyond the point of constant infusion. The osmolality of plasma was measured at the beginning and end of each perfusion and in fluid collected continuously for 1 hour from each of the four collecting tubes. The plasma osmolality was subtracted from the osmolality of fluid collected from the four sampling sites to obtain the 


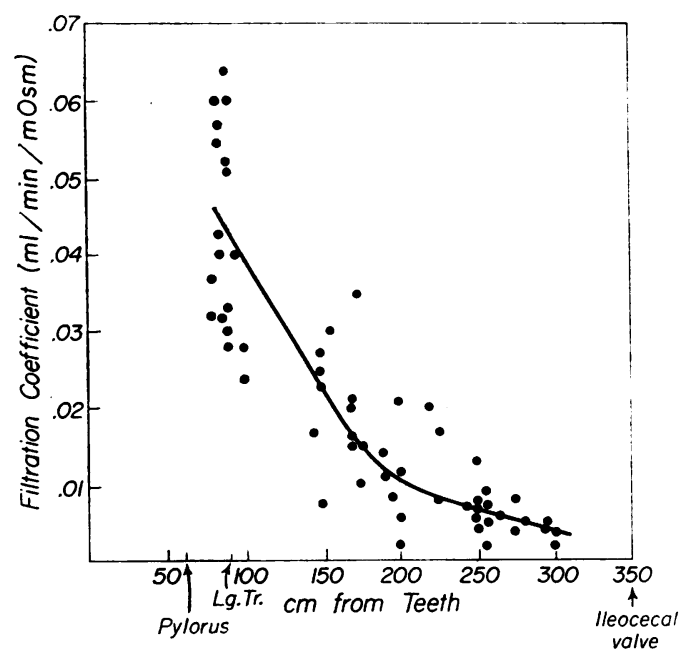

Fig. 2. The volume of WATER MOVEMENT PER MINUTe PER MILLIOSMOLE GRADIENT IN 20-CM SEGMENTS OF SMALL INTESTINE IN RESPONSE TO HYPERTONIC MANNITOL. Mannitol is assumed to exert its full theoretic osmotic pressure (see text), and results therefore are a measure of the filtration coefficient of the intestinal mucosa. The line was fitted visually. Lg. Tr. = ligament of Treitz.

theoretic osmotic pressure gradient at each point. In all four studies a straight-line relation was obtained when the logarithm of the osmotic pressure gradient was plotted against distance. In all subsequent studies the mean osmotic pressure gradient in the test segment was determined by plotting the proximal and distal osmotic pressure gradients on semilogarithmic paper and taking the midpoint value.

By dividing the calculated volume changes induced by hypertonic mannitol by the mean osmotic pressure gradient between plasma and luminal fluid, the filtration coefficient at different levels of the small intestine was obtained. The results are shown in Figure 2. There was a progressive fall in water movement from proximal to distal segments of the small intestine; in the area of the ligament of Treitz approximataely $0.044 \mathrm{ml}$ per minute of water moved into the $20-\mathrm{cm}$ test segment per mOsm gradient, whereas in the lower ileum the corresponding value was 0.005 . We conclude, therefore, that the upper intestine has a much higher permeability to the bulk flow of water than does the lower small intestine.

Water movement produced by other solutes compared to that induced by mannitol. Preliminary studies showed that when intestinal segments were perfused with solutions made hypertonic by urea, erythritol, or $\mathrm{NaCl}$, the osmotic pressure gradient between intestinal lumen and blood fell exponentially as a function of length in a fashion similar to that observed with mannitol. Therefore, mean osmotic pressure gradient and net water movement per unit osmotic pressure gradient were calculated as described for mannitol in the previous section.

At a given level in the small intestine in a given individual the rate of fall in osmolality was approximately the same for hypertonic solutions of mannitol and urea (18 studies), mannitol and erythritol (18 studies), and mannitol and sodium chloride (13 studies). This phenomenon is probably due to the fact that fall in osmolality results from two different but reciprocally related factors : penetration of the membrane by the solute and bulk flow of water into the intestinal lumen. For large molecules that are unable to penetrate, the fall in osmolality is due entirely to bulk water flow. For smaller molecules, both mechanisms are operative but in a reciprocal fashion: the greater the solute penetration, the less the bulk flow of water, and vice versa.

The results of studies comparing water movement induced by mannitol and urea, mannitol and erythritol, and mannitol and sodium chloride are shown in Figures 3, 4, and 5. On the left side of each Figure water movement per minute per milliosmole gradient for each pair of solutes is shown at different levels of the small intestine. In the upper intestine mannitol produced more water movement than did the other solutes, but in the lower intestine the other solutes pulled almost as much water as mannitol. This can be appreciated more clearly in the right side of each Figure, which plots the ratio of water movement caused by urea, erythritol, or sodium chloride divided by that produced by mannitol in the same test segment. The ratio was low in the upper intestine and rose progressively, approaching unity in the lower ileum. Average values for the osmotic ratio in the upper intestine ( 80 to $200 \mathrm{~cm}$ from the teeth) were 0.48 for urea, 0.64 for erythritol, and 0.58 for sodium chloride. Corresponding values for the lower intestine (200 to $300 \mathrm{~cm}$ from the teeth) were 0.89 for urea, 0.98 for erythritol, and 1.0 for sodium chloride. In the sodium chloride studies in the 

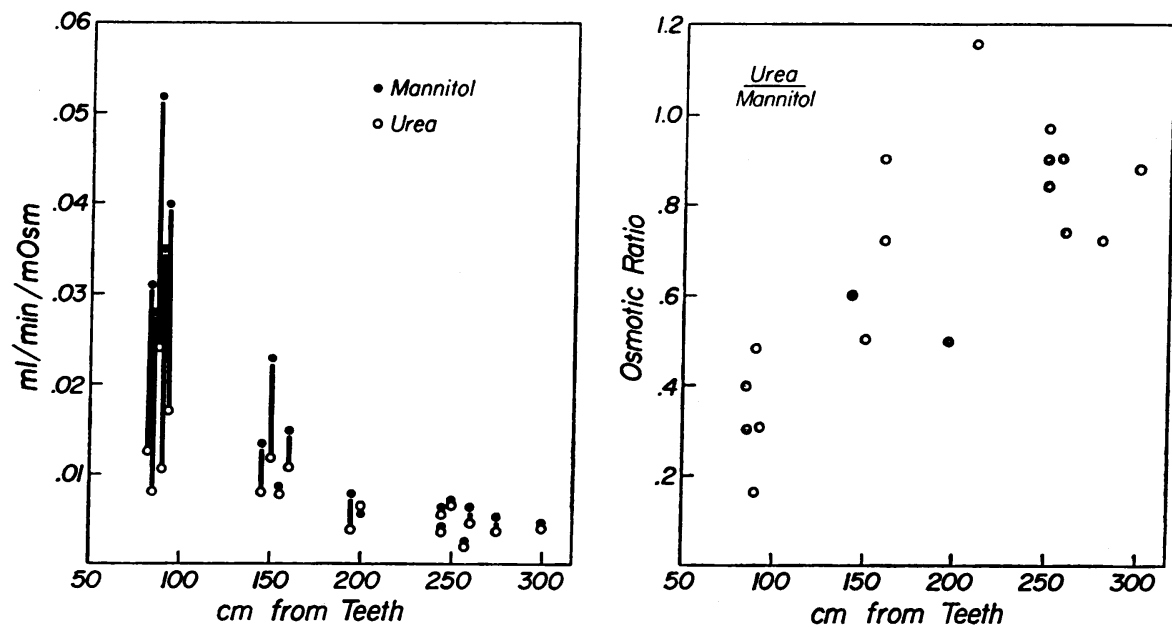

Fig. 3. Water movement in 20-CM SEgments of SMALl intestine IN RESPonse to OSMOTIC GRADIENTS EXERTED BY UREA AND MANNITOL (LEFT SIDE) AND THE RATIO OF WATER MOVEMENT PRODUCED BY UREA DIVIDED BY THAT PRODUCED BY MANNITOL (RIGHT SIDE).

lower intestine one value for the osmotic ratio was unreasonably high (1.50). If this value is excluded, the mean osmotic ratio for sodium chloride in the lower small intestine was 0.95 .

Concentration of sodium in filtrate. To determine whether flow of water into the intestine in response to osmotic pressure gradients can also pull plasma sodium salts into the lumen, the concentration of sodium in the filtrate was calculated. From the concentration of PEG, net movement of water into the $20-\mathrm{cm}$ test segment was known. In 46 of the hypertonic mannitol perfusion studies, sodium concentration in fluid obtained from each collecting site was measured, and net sodium movement into the test segment was determined. Knowing net water and sodium movements, we calculated the sodium concentration in water moving across the mucosal cells in response to osmotic gradients.

The concentration of sodium in the filtrates averaged $60 \pm 15.9$ (SD) $\mathrm{mEq}$ per $\mathrm{L}$ in the upper jejunum ( 80 to $125 \mathrm{~cm}$ from the teeth), $34 \pm 19.3$ $\mathrm{mEq}$ per $\mathrm{L}$ in the mid-intestine $(125$ to $200 \mathrm{~cm})$, and $10 \pm 25.7 \mathrm{mEq}$ per $\mathrm{L}$ in the lower ileum (200 to $300 \mathrm{~cm}$ ).

\section{Discussion}

The present studies demonstrate several important characteristics of the osmotic flow of water across the mucosa of the small intestine. First, the flow of water induced by known effective osmotic pressure gradients (i.e., filtration coefficient) is approximately ninefold greater in the first part of the jejunum than in the terminal ileum. Second, the ability of a given concentration gradient to promote the movement of water is not constant but varies with the molecular size of the substance used. For instance, in the jejunum the flow of water per minute per milliosmole gradient was over two times as great with mannitol as with urea. Finally, the variation in the effective osmotic pressure exerted per unit concentration gradient by different solutes was more marked in the upper than in the lower small intestine. In the jejunum a given concentration gradient of urea was approximately $48 \%$ as effective as was mannitol, whereas in the ileum the effective osmotic pressure with similar concentration gradients of urea and mannitol was approximately equal.

Staverman (5) has pointed out that the ability of a nonlipid-soluble solute to generate effective osmotic pressure is inversely related to its ability to permeate the membrane, which in turn is dependent upon molecular size of the substance in question relative to the size of the water-filled pores that penetrate the membrane (6). To make this relationship more explicit, the term "reflection coefficient" has been introduced, which is defined as the ratio of the effective to the theoretic osmotic pressure (see footnote 1). Thus, for a solute that is as large as or larger than the water- 

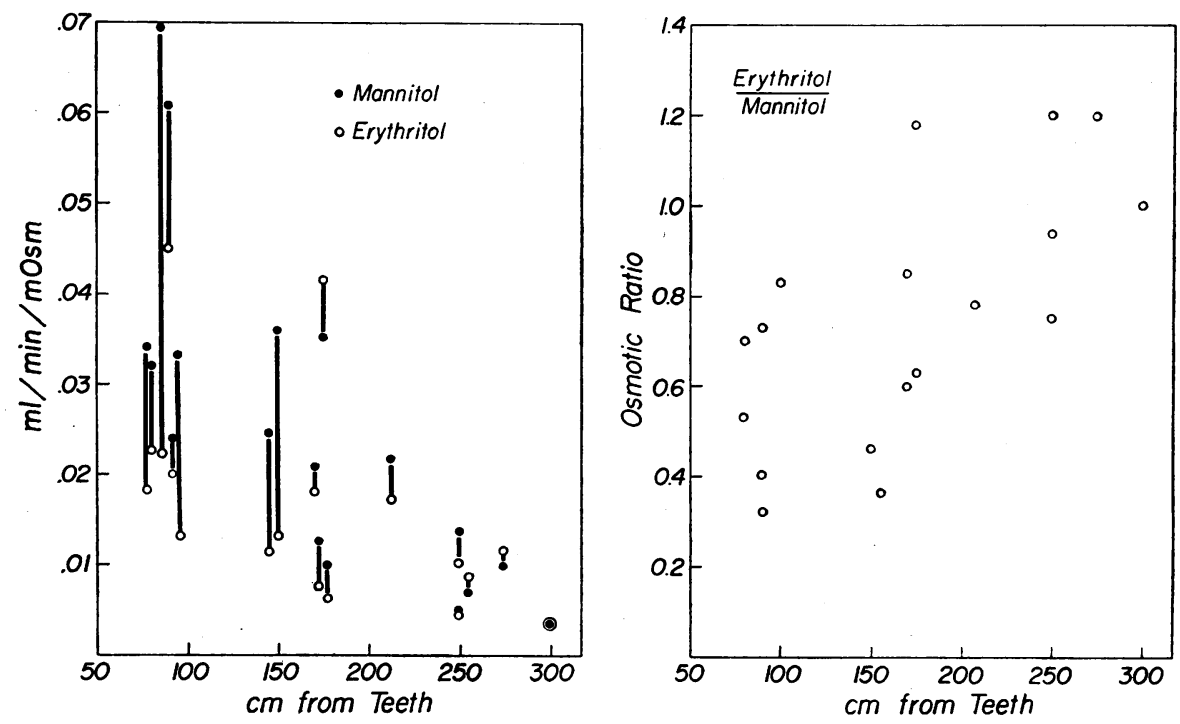

Fig. 4. Water movement in 20-CM SEgments of SMall INTESTine IN RESPonse to OSMOTIC GRADIENTS EXERTED BY ERYTHRITOL AND MANNITOL (LEFT SIDE) AND THE RATIO OF WATER MOVEMENT PRODUCED BY ERYTHRITOL DIVIDED BY THAT PRODUCED BY MANNITOL (RIGHT SIDE).

filled pores, the effective and theoretic osmotic pressures will be equal, and the reflection coefficient will be 1 . In contrast, for solutes that are smaller than the pore the effective osmotic pressure will be less than the theoretic value, and the reflection coefficient will fall between 0 and 1.0.

The data in the present studies can be used in estimating the reflection coefficients of urea, erythritol, and sodium chloride in the small intestine. Since mannitol was shown not to be absorbed, we assumed that it exerts its full theoretic osmotic pressure and has a reflection coefficient of 1.0. Therefore, $\sigma_{\mathbf{X}}=Q_{\mathbf{x}} / Q_{\mathbf{M}}$, where $Q_{\mathbf{M}}$ and $Q_{\mathbf{X}}$ represent the volume of water flow induced by known theoretic osmotic gradients of mannitol and solute $\mathrm{X}$, respectively, and $\sigma_{\mathbf{X}}$ is the reflection coefficient of solute $\mathrm{X}$.

The ratio of the osmotic flows for urea, erythritol, and sodium chloride relative to mannitol is, therefore, a measure of the reflection coefficients of these solutes. These values have been calculated for each experiment and are presented in the righthand side of Figures 3, 4, and 5. Since the reflection coefficients for all of these solutes were higher in the ileum than in the jejunum, one may conclude that the lower small intestine is less permeable than the upper small intestine.
Although differences in the filtration coefficients in the upper and lower intestine might be partly explained on the basis of differences in surface area or blood flow, the markedly different reflection coefficients for urea, erythritol, and sodium chloride indicate a basic difference in the intrinsic permeability of the jejunum and ileum. There is good evidence that bulk flow of water $(14,16)$ and small lipid-insoluble solutes such as urea and erythritol $(1,6)$ penetrate cell membranes through water-filled channels or pores. The over-all permeability of the cell membrane to water and watersoluble solutes, therefore, is determined to a large extent by the number and characteristics of these channels. Since, however, the reflection coefficients of the various solutes are independent of both the number of channels and their length, it seems reasonable to assume that the differences in both the filtration coefficients and the reflection coefficients in the jejunum and ileum are due to differences in the effective cross-sectional area of each channel.

Several factors make it difficult to assess the cross-sectional area of these channels in any given area of the intestine. First, there are at least three membranes in series (luminal and basal epithelial cell membranes and capillary membrane of the 

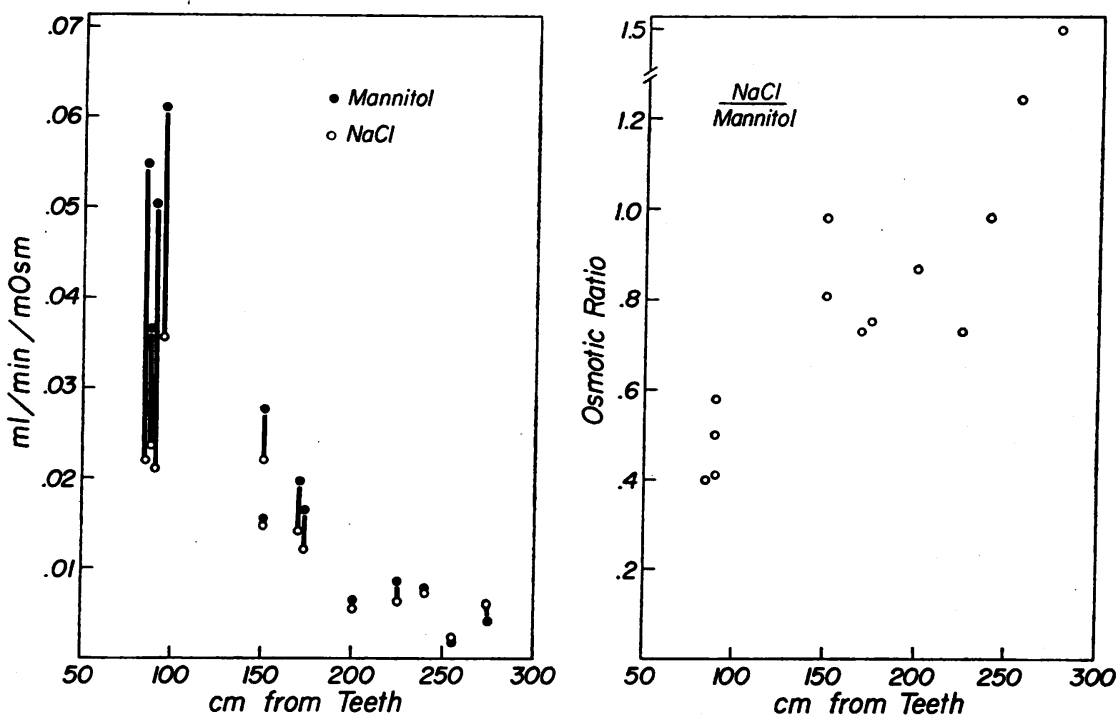

Fig. 5. WATER MOVEMENT IN 20-CM SEgMENTS OF SMALL INTESTINE IN RESPONSE TO OSMOTIC GRADIENTS EXERTED BY SODIUM CHLORIDE AD MANNITOL (LEFT SIDE) AND THE RATIO OF WATER MOVEMENT PRODUCED BY SODIUM CHLORIDE DIVIDED BY THAT PRODUCED BY MANNITOL (RIGHT SIDE).

venous capillaries) that determine over-all permeability. Second, the channels in each of these different membranes might differ widely in size. Finally, the channels in any given membrane probably do not have uniform dimensions. For purposes of mathematical analysis, and for interpreting our results, however, it is useful to consider the intestinal barrier as a single membrane penetrated by right-cylindrical pores of uniform dimensions. In this way an effective pore radius of the intestine can be calculated with concepts of Renkin (17) and Solomon (6). It should be stressed that the calculated effective pore radius does not apply to any single membrane separating the intestinal lumen from blood; rather, the calculated values indicate the size that right-cylindrical pores of uniform size would have to be in a single membrane to have given the experimentally determined reflection coefficients for urea and erythritol that we found in the human small intestine.

Using formulas derived by Renkin (17), Solomon (6) has pointed out that curves can be drawn relating the reflection coefficient of a nonlipidsoluble solute to the pore radius of a membrane. In Figure 6, three such curves are shown, one for urea (molecular radius, $2.3 \mathrm{~A}$ ), one for erythritol (molecular radius, $3.2 \mathrm{~A}$ ), and one for mannitol (molecular radius, 4.0 A). These radii were determined from molecular models by Schultz and Solomon (18) and are the same as those used by Lindemann and Solomon in calculating the equivalent pore radius of the luminal surface of the rat jejunum (4).

By using the curves in Figure 6, the effective pore radius in any area of the intestine can be determined from the reflection coefficients for urea and erythritol obtained in that region. For example, in the jejunum the average reflection coefficient for urea of 0.48 intercepts the urea curve at an effective pore radius of $6.7 \mathrm{~A}$, whereas the reflection coefficient of erythritol intercepts its curve at a pore radius of $8.8 \mathrm{~A}$. In striking contrast, the corresponding intercept points in the ileum indicate values of 3.0 and $3.8 \mathrm{~A}$, respectively. Thus, the effective pore radius in the jejunum is approximately twice the size of the effective pore radius in the ileum. Since there was a progressive rise in the reflection coefficients of urea and erythritol from upper jejunum to lower ileum, one can conclude that there is a progressive decrease in effective pore size in going from the upper to the lower small intestine.

Theoretically, mannitol. which has a molecular radius of $4.0 \mathrm{~A}$, should be able to penetrate the 


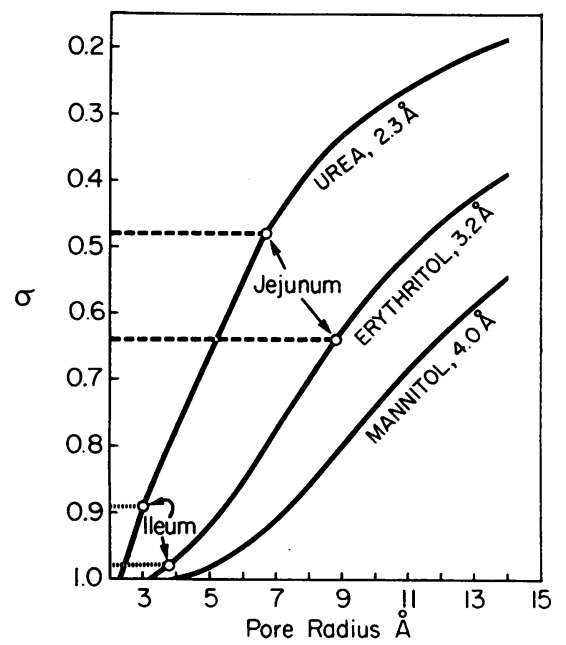

Fig. 6. Theoretic CURVES DePicting the RELAtionSHIP BETWEEN THE REFLECTION COEFFICIENT $(\sigma)$ AND MEMBRANE PORE RADIUS FOR THE NONLIPID, NONELECTROLYTE SOLUTES USED IN THE PRESENT STUDY. These curves were calculated by computer from Renkin's equations (17) as used by Solomon (6). The reflection coefficients of urea and erythritol in jejunum and ileum are indicated.

upper small intestine (effective pore radius of 7 to $8.5 \mathrm{~A}$ ) and therefore should have a reflection coefficient of less than 1.0. Our failure to demonstrate absorption of mannitol in the jejunum (Figure 1) most likely is because molecules of $4 \mathrm{~A}$ have a theoretic reflection coefficient of 0.82 to 0.92 when related to a membrane with pores the size estimated for the jejunum. With this high reflection coefficient, the absorption rate of mannitol would be extremely slow and perhaps undetectable by our method. Our assumption that the reflection coefficient of mannitol is 1.0 might. therefore, possibly result in an error when calculating the pore radius of the upper small intestine. This error, however, would be in the direction of overestimating the reflection coefficients for urea and erythritol in the jejunum (but not in the ileum, where the reflection coefficient of mannitol would be expected to be 1) and therefore underestimating the effective jejunal pore size. Thus. the difference in effective pore radius between the upper and lower small intestine may be slightly greater than our calculations indicate.

The variation in effective pore size affords a reasonable explanation for some of the differences in absorptive characteristics of the upper and lower small intestine. For example, Fordtran, Clodi,
Soergel, and Ingelfinger (19) found that xylose was absorbed rapidly in the jejunum, but that absorption decreased progressively in the more distal segments, and almost none was absorbed in the lower ileum. Since pentoses have a molecular radius of approximately $3.5 \mathrm{~A} \mathrm{(18),} \mathrm{it} \mathrm{is} \mathrm{reason-}$ able to suggest that their absorption profile is determined primarily by the gradient of effective pore size in the intestine.

Of greater physiologic importance is the effect of variations in effective pore size on the absorption of water and electrolytes. As shown in Figure 2 , the filtration of water induced by known osmotic pressure gradients was ninefold greater in the upper jejunum than in the lower ileum. This difference in filtration coefficient parallels the change in pore size and is therefore at least partially explainable on the basis of Poiseuille's law, which states that the flow of water through cylindrical pores is proportional to the fourth power of the radius (20). Bulk water flow is, therefore, very sensitive to pore size, and a twofold difference in pore size could easily account for a ninefold difference in filtration coefficients.

The marked differences in the rate of bulk flow of water in the jejunum and ileum are in striking contrast to the relatively slight differences in the rates of unidirectional diffusion of water previously reported by Fordtran and his colleagues (7) and by Whalen, Harris, and Soergel (21). We have, furthermore, verified this apparent discrepancy in the same intestinal segments of jejunum and ileum of three normal subjects. This disparity between diffusion and bulk flow is not, however. unique to the small intestine. For instance, Andersen and Ussing (16) found that enlarging the pore size of the frog skin by antidiuretic hormone has a marked effect on the bulk flow of water (increased three- to fourfold) but only a slight effect on the diffusion of water (increased less than 1.5fold). One reason for this discrepancy, as previously pointed out by others, is that diffusion of water is proportional to the second, but bulk flow to the fourth, power of the radius of the pore. A small change in pore radius, therefore, will have a much greater effect on bulk flow than on diffusion of water. Berliner (22) has suggested that an additional factor might be changes in the shape of a pore in such a way that resistance to bulk flow is altered without influencing the total pore area 
available for diffusion of water. Since in practically every instance the force driving net movement of water across a living membrane is either hydrostatic or osmotic pressure, the factors governing the bulk flow of water, rather than diffusional flow, are of primary importance. The failure of isotopic diffusion to depict the true differences in the upper and lower intestine illustrates the futility in using isotopic techniques alone to characterize water movement across biologic membranes.

Water absorption in the small intestine is generally considered to occur passively as a consequence of the active absorption of glucose, sodium, and so on. The transport of solute is believed to create a local osmotic pressure on the blood side of the intestinal cell membrane that promotes the bulk flow of water through pores. Just as bulk flow of water into the intestinal lumen in response to perfusion with a hypertonic solution was much less in the ileum, net water absorption secondary to active solute transport will be relatively restricted in the ileum compared to the jejunum. Stated in another way, in order to achieve the same rate of water absorption in the two areas a higher local osmotic gradient would be required in the ileum than in the jejunum. This is the probable explanation of Visscher's observation that during absorption of initially isotonic solutions, jejunal solutions remain isotonic, whereas ileal solutions become slightly but definitely hypotonic to plasma (23).

As a final point, the present studies provide a means of evaluating the extent to which the absorption of water from the intestine may facilitate the movement of solutes across the intestinal mucosa. In this process, which has been termed "solvent drag," the solutes in effect are caught in the moving stream of water and swept through the pores of the intestinal cells. The extent to which solvent flow across a membrane will promote the net movement of a given solute, however, is directly related to the reflection coefficient of that solute, as discussed by Kedem and Katchalsky (24). This relationship is explicitly stated by the equation, $J_{s}=C_{s}\left(1-\sigma_{s}\right) J_{V}$, where $J_{s}$ is the rate of solute movement due to solvent drag, $J_{v}$ the rate of solvent flow, and $C_{8}$ the concentration of the substance in the parent fluid. Stated in another way, the concentration of the substance in the fil- trate or absorbate $\left(J_{8} / J_{\nabla}\right)$ is equal to its concentration in the original fluid times $\left(1-\sigma_{s}\right)$. If, therefore, the reflection coefficient for a given substance is very low, solvent drag will have a large effect on its movement, whereas if the $\sigma$ is very high, solvent flow will have little or no effect. Thus, in the upper jejunum where the reflection coefficient for $\mathrm{NaCl}$ is relatively small $(0.45)$, the bulk flow of water should have a significant effect on its transport rate; $\mathrm{NaCl}$ concentration in a filtrate or absorbate should be roughly $55 \%$ of its concentration in the parent fluid. In the lower small intestine, where the reflection coefficient for $\mathrm{NaCl}$ approaches 1.0, solvent drag should have little or no effect on its movement. The effect of solvent drag on the movement of sodium salts is clearly demonstrated in studies with hypertonic mannitol. In the upper jejunum the concentration of sodium salts in the filtrate pulled from plasma into the lumen was approximately $60 \mathrm{mEq}$ per L, or approximately $40 \%$ of plasma concentration; this figure is in reasonable agreement with that predicted from the reflection coefficient. In contrast, in the lower ileum the concentration of sodium in the filtrate was low (average, $10 \mathrm{mEq}$ per L). These different concentrations of sodium in the filtrates in the upper and lower small intestine serve as independent confirmation of the different values for $\sigma_{\mathrm{NaCl}}$ in these two areas of the intestine.

\section{Summary}

Water movement into the small intestine in response to osmotic gradients created by nonlipidsoluble solutes of graded molecular size (urea, 2.3 A; erythritol, 3.2 A; and mannitol, 4.0 A) and by sodium chloride was measured in normal subjects. Mannitol was not absorbed to a measurable extent, and this solute was therefore assumed to be capable of exerting its full theoretic osmotic pressure. Water movement in response to osmotic gradients created by mannitol was, therefore, a reasonably accurate measure of the filtration coefficient of the small intestinal mucosa. It was found that there was a progressive fall in bulk water movement from proximal to distal segments of the small intestine in response to hypertonic mannitol, the upper intestine showing a ninefold higher permeability to water flow than the lower small intestine. 
The ability of urea, erythritol, and sodium chloride to exert osmotic pressure, relative to that exerted by mannitol, was found to vary at different levels of the small intestine. In the jejunum, urea, erythritol, and $\mathrm{NaCl}$ were only 45 to $60 \%$ as effective as mannitol in inducing bulk water flow, whereas in the ileum they were almost as effective as mannitol. These data indicate a basic difference in the permeability of the upper and lower small intestine that cannot be explained by differences in surface area or blood flow. The observations can be explained by differences in the radius of pores in the membranes of the small intestine. With the formulas and concepts of Renkin and Solomon the effective pore radius of the jejunum was calculated to be at least two times larger than that of the ileum.

\section{References}

1. Höber, R., and J. Höber. Experiments on the absorption of organic solutes in the small intestine of rats. J. cell. comp. Physiol. 1937, 10, 401.

2. Schanker, L. S., D. J. Tocco, B. B. Brodie, and C. A. M. Hogben. Absorption of drugs from the rat small intestine. J. Pharmacol. exp. Ther. 1958, $123,81$.

3. Hogben, C. A. M., D. J. Tocco, B. B. Brodie, and L. S. Schanker. On the mechanism of intesti.al absorption of drugs. J. Pharmacol. exp. Ther. 1959, 125, 275.

4. Lindemann, B., and A. K. Solomon. Permeability of luminal surfaces of intestinal mucosal cells. J. gen. Physiol. 1962, 45, 801.

5. Staverman, A. J. The theory of measurement of osmotic pressure. Recueil 1951, 70, 344.

6. Solomon, A. K. Measurement of the equivalent pore radius in cell membranes in Membrane Transport and Metabolism, A. Kleinzeller and A. Kotyk, Eds. New York, Academic Press, 1960, p. 94.

7. Fordtran, J. S., R. Levitan, V. Bikerman, B. A. Burrows, and F. J. Ingelfinger. The kinetics of water absorption in the human intestine. Trans. Ass. Amer. Phycns 1961, 74, 195.

8. Jacobson, E. D., D. C. Bondy, S. A. Broitman, and J. S. Fordtran. Validity of polyethylene glycol in estimating intestinal water volume. Gastroenterology 1963, 44, 761.

9. Cooper, H., R. Levitan, J. S. Fordtran, and F. J. Ingelfinger. A method for studying absorption of water and solute from the human small intestine. In preparation.
10. Malawer, S. J., M. Ewton, J. S. Fordtran, and F. J. Ingelfinger. Interrelation between jejunal absorption of sodium, glucose and water in man. J. clin. Invest. 1965, 44, 1072.

11. Fisher, R. B. The absorption of water and of some small solute molecules from the isolated small intestine of the rat. J. Physiol. (Lond) 1955, 130, 655.

12. Hyden, S. A turbidometric method for the determination of higher polyethylene glycols in biologic materials. Annals of the Agricultural College of Sweden 1955, 22, 139.

13. Corcoran, A. C., and I. H. Page. A method for the determination of mannitol in plasma and urine. J. biol. Chem. 1947, 170, 165.

14. Curran, P. F. Na, $\mathrm{Cl}$ and water transport by rat ileum in vitro. J. gen. Physiol. 1960, 43, 1137.

15. Hindle, W., and C. F. Code. Some differences between duodenal and ileal sorption. Amer. J. Physiol. 1962, 203, 215.

16. Andersen, B., and H. H. Ussing. Solvent drag on non-electrolytes during osmotic flow through isolated toad skin and its response to antidiuretic hormone. Acta physiol. scand. 1957, 39, 228.

17. Renkin, E. M. Filtration, diffusion, and molecular sieving through porous cellulose membranes. J. gen. Physiol. 1954, 38, 225.

18. Schultz, S. G., and A. K. Solomon. Determination of the effective hydrodynamic radii of small molecules by viscometry. J. gen. Physiol. 1961, 44, 1189.

19. Fordtran, J. S., P. F. Clodi, K. H. Soergel, and F. J. Ingelfinger. Sugar absorption tests, with special reference to 3-O-methyl-d-glucose and d-xylose. Ann. intern. Med. 1962, 57, 883.

20. Pappenheimer, J. R., E. M. Renkin, and L. M. Borrero. Filtration, diffusion and molecular sieving through peripheral capillary membranes. A contribution to the pore theory of capillary permeability. Amer. J. Physiol. 1951, 167, 13.

21. Whalen, G., J. Harris, and K. Soergel. Bidirectional flux of sodium and water in the human small intestine (abstract). Gastroenterology 1965, 48, 859.

22. Berliner, R. W. Membrane transport. Rev. mod. Physics 1959, 31, 342.

23. Visscher, M. B. Transport of water and electrolyte across intestinal epithelia in Mctabolic Aspects of Transport across Cell Membranes, Q. R. Murphy, Ed. Madison, University of Wisconsin Press, 1957, p. 57.

24. Kedem, O., and A. Katchalsky. A physical interpretation of the phenomenological coefficients of membrane permeability. J. gen. Physiol. 1961, 45, 143. 